\title{
EXISTENCE AND MULTIPLICITY RESULTS FOR THE BOUNDARY VALUE PROBLEM OF NONLINEAR FRACTIONAL DIFFERENTIAL EQUATIONS
}

\section{LIJUN PAN}

Abstract. In this paper, we devote to investigation of the existence of positive solutions for the boundary value problem of nonlinear fractional differential equations

$$
\left\{\begin{array}{l}
D_{0^{+}}^{\alpha} u(t)+f(t, u(t))=0,0<t<1, \\
u(0)=u^{\prime}(0)=\cdots u^{(n-2)}(0)=D_{0^{+}}^{\beta} u(1),
\end{array}\right.
$$

where $D_{0^{+}}^{\alpha}, D_{0^{+}}^{\beta}$ are the standard Riemann-Liouville fractional derivative, $n-1<\alpha \leqslant n$, $n-2 \leqslant \beta \leqslant n-1, n \geqslant 3$. By means of constructing an exact cone of the Banach space and fixedpoint theorem, some new multiplicity results for the boundary value problem are obtained. The interest is that we establish the theorems of the existence of infinitely many positive solutions.

Mathematics subject classification (2010): 26A33, 34B15.

Keywords and phrases: Boundary value problem, fractional differential equations, positive solution, fixed-point theorem.

\section{REFERENCES}

[1] S. G. Samko, A. A. Kilbas, O. I. Marichev, Fractional Integral And Derivatives (Theory and Applications), Gordon and Breach, Switzerland, 1993.

[2] I. Podlubny, Fractional Differential Equations, in: Mathematics in Science and Engineering, vol. 198, Academic Press, New Tork, London, Toronto, 1999.

[3] O. P. AgRawal, Formulation of Euler-Lagrange equations for fractional variational problems, J. Math. Anal. Appl. 272 (2002) 368-379.

[4] A. BABAKHANI, V. D. GEJJi, Existence of positive solutions of nonlinear fractional differential equations, J. Math. Anal. Appl. 278 (2003) 434-442.

[5] Z. B. BAI, H. S. LU, Positive solutions for boundary value problem of nonlinear fractional differential equation, J. Math. Anal. Appl. 311 (2005) 495-505.

[6] R. P. AgARWAL, M. Benchohra, S. HAMAni, Boundary value problem for fractional differential equations, Adv. Stud. Contemp. Math. 16 (2) (2008) 181-196.

[7] A. A. Kilbas, H. M. Srivastava, J. J. Trujillo, Theory and Applications of Fractional Differential Equations, in: North-Holland Mathematics Studies, vol. 204, Elsevier Science B. V., Amsterdam, 2006.

[8] H. M. SRivastava, R. K. Saxena, Operators offractional integration and their applications, Appl. Math. Comput. 118 (2001) 1-52.

[9] B. AhmAD, S. SivasundarAm, Existence and uniqueness results for nonlinear boundary value problems of fractional differential equations with separated boundary conditions, Commun. Appl. Anal. 13 (2009) 121-228.

[10] H. M. Srivastava, S. Owa, K. Nishimoto, Some fractional differintegral equations, J. Math. Anal. Appl. 106 (1985) 360-366.

[11] V. Lakshmikantham, A. S. VATSAla, General uniqueness and monotone iterative or fractional differential equations, Appl. Math. Lett. 21 (2008) 828-834. 
[12] C. BAI, J. FANG, The existence of a positive solution for a singular coupled system of nonlinear fractional dierential equations, Appl. Math. Comput. 150 (2004) 611-621.

[13] V. Lakshmikantham, A. S. VATSAla, Basic theory of fractional dierential equations, Nonlinear Anal. TMA. 69 (2008) 2677-2682.

[14] E. Kaufmann, E. Mboumi, Positive solutions of a boundary value problem for a nonlinear fractional differential equation, Electron. J. Qual. Theory Differ. Equ. 2008 (2008), No. 3, 1-11.

[15] M. A. KRasnosels KiI, Positive Solutions of Operator Equations, Groningen, Netherlands, 1964.

[16] D. JiAnG, C. YUAN, The properties of the Green function for Dirichlet-type boundary value problem of a nonlinear fractional differential equations and its application, Nonlinear Anal. 72 (2010) 710 719 .

[17] C. F. LI, X. N. LuO, Y. ZHOU, Existence of positive solution of the boundary value problem for nonlinear fractional differential equations, Comput and Math Appl. 59 (2010) 1363-1375.

[18] S. H. LiAng, J. H. ZHANG, Positive solutions for boundary value problem of nonlinear fractional differential equation, Nonlinear Anal. 71 (2009) 5545-5550. 